FROM CAS \& CAE MEMBERS

-PROFILE•
December 2018 Vol.61 No.12: 1463-1464

https://doi.org/10.1007/s11427-018-9436-y

\title{
Profile of Dr. Hualan Chen
}

Dr. Hualan Chen is a virologist whose research focuses on understanding influenza virus and developing vaccines against this virus. She studied veterinary medicine as her undergraduate and graduate majors in Gansu Agricultural University, receiving her Bachelor degree and Master degree in 1991 and 1994, respectively. In 1997, she received her Ph. D. from the Graduate School of the Chinese Academy of Agricultural Sciences (CAAS). After three years of postdoctoral research at the Centers for Disease Control and Prevention in the United States, she was offered a professorship in 2002 at the Harbin Veterinary Research Institute of CAAS and was appointed as the Director of the National Avian Influenza Reference Laboratory. Her laboratory was accredited as the OIE Avian Influenza Reference Laboratory in 2008 and as the FAO Animal Influenza Reference Center in 2013.

Dr. Chen's research has been supported by several important grants, including the National Outstanding Young Investigator Fund from the National Natural Science Foundation of China (2008), the Chinese National Key Basic Research Program (the 973 Program) from the Ministry of Science and Technology (2010), and the Science Fund of the Creative Research Group from the National Natural Science Foundation of China (2015).

\section{CONTRIBUTIONS TO H5N1 INFLUENZA VIRUS RESEARCH AND CONTROL}

Avian influenza viruses (AIVs) are important zoonosis pathogens; therefore, their characterization and control are important for both animal and human health. The H5 subtype avian influenza viruses have caused severe animal and public health problems around the world. Dr. Chen's group investigated a series of $\mathrm{H} 5 \mathrm{~N} 1 \mathrm{AIVs}$ isolated from domestic poultry and wild birds and found that these viruses had complicated genotypes with clearly distinct phenotypes in terms of their replication and lethality in mice (Chen et al.,

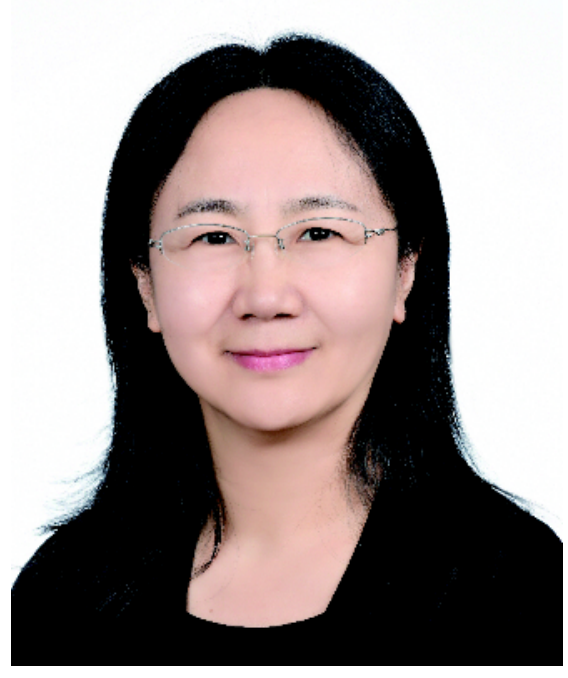

2004; Chen et al., 2006; Li et al., 2010). Most importantly, they found that $\mathrm{H} 5 \mathrm{~N} 1 \mathrm{AIV}$ s have progressively acquired the ability to infect and kill mice while circulating in nature (Chen et al., 2004). They found several molecular makers that contribute to the host range, virulence, receptor binding, and transmission of avian influenza viruses ( $\mathrm{Li}$ et al., 2005; Li et al., 2006; Jiao et al., 2008; Zhu et al., 2008; Gao et al., 2009). Moreover, they found that H5N1 virus could reassort with human H1N1 virus and then become highly transmissible in mammals (Zhang et al., 2013b). These scientific findings have significantly increased our knowledge and provided important information for the control of poultry $\mathrm{H} 5 \mathrm{~N} 1$ influenza and for human $\mathrm{H} 5 \mathrm{~N} 1$ pandemic preparedness. In recognition of these contributions, Dr. Chen was awarded a National Prize for Natural Sciences in 2013.

Dr. Chen has established several platforms for avian influenza vaccine development (Tian et al., 2005; Ge et al., 2007; Liu et al., 2011; Li et al., 2014). By using these platforms, she developed a novel inactivated H5N1 vaccine and two live virus-vectored H5 vaccines (a Newcastle disease virus-vectored vaccine and a duck enteritis virus-vectored 
vaccine) (Ge et al., 2007; Liu et al., 2011). Over 230 billion doses of these vaccines have been used in poultry in China and other countries; the use of these vaccines has played a major role in the control of H5N1 influenza and has had a huge impact on the poultry industry and other affected communities. For her contribution to vaccine development and its application, Dr. Chen was awarded a National Prize for Scientific and Technological Progress in 2005 and the National Prize for Technological Invention in 2007.

\section{CONTRIBUTIONS TO H7N9 INFLUENZA VIRUS RESEARCH AND CONTROL}

A new H7N9 influenza virus emerged in China In 2013 and caused five waves of human infection, with the second to fifth waves starting around the beginning of October of each year. Dr. Chen's group played an important role in the successful control of H7N9 influenza in China.

Dr. Chen and her team performed extraordinary work to locate the source of the virus and to characterize its biological properties. Their comprehensive studies provided a complete evolutionary picture of $\mathrm{H} 7 \mathrm{~N} 9$ viruses in nature. Importantly, the detection of H7N9 highly pathogenic virus in early 2017 and studies in animal models that revealed the high pandemic potential of the H7N9 viruses and their increased threat to human health provided essential information for the active control of H7N9 influenza in China (Shi et al., 2013; Zhang et al., 2013a, Shi et al., 2017, Shi et al., 2018).

To control the H7N9 influenza viruses, Dr. Chen and her team developed an $\mathrm{H} 5 / \mathrm{H} 7$ bivalent inactivated vaccine and tested it extensively in the laboratory and poultry farms. In September 2017, the vaccine began to be used in poultry and has successfully prevented the prevalence of H7N9 virus in chickens, thereby eliminating human infection with H7N9 virus (Shi et al., 2018; Zeng et al., 2018).

In recognition of her contribution to avian influenza research and control, Dr. Chen was selected as one of "the 10 people who mattered in 2013" by the prominent interdisciplinary scientific journal Nature. She also received several important local and international awards and honors, including the Chinese Young Women in Science Fellowship (2005), the Chinese Agriculture Elite Award (2005), the Ho Leung Ho Lee Foundation Prize for Scientific and Technological Innovation (2006), National Outstanding Scientific and Technological Talent Award (2016), and the L'OréalUNESCO Women in Science International Award (2016). In 2017, she was elected as a member of the Chinese Academy of Sciences.

Chen, H., Deng, G., Li, Z., Tian, G., Li, Y., Jiao, P., Zhang, L., Liu, Z., Webster, R.G., and Yu, K. (2004). The evolution of H5N1 influenza viruses in ducks in Southern China. Proc Natl Acad Sci USA 101, 10452-10457.

Chen, H., Li, Y., Li, Z., Shi, J., Shinya, K., Deng, G., Qi, Q., Tian, G., Fan, S., Zhao, H., et al. (2006). Properties and dissemination of H5N1 viruses isolated during an influenza outbreak in migratory waterfowl in western China. J Virol 80, 5976-5983.

Ge, J., Deng, G., Wen, Z., Tian, G., Wang, Y., Shi, J., Wang, X., Li, Y., Hu, S., Jiang, Y., et al. (2007). Newcastle disease virus-based live attenuated vaccine completely protects chickens and mice from lethal challenge of homologous and heterologous H5N1 avian influenza viruses. J Virol 81, $150-158$.

Gao, Y., Zhang, Y., Shinya, K., Deng, G., Jiang, Y., Li, Z., Guan, Y., Tian, G., Li, Y., Shi, J., et al. (2009). Identification of amino acids in HA and $\mathrm{PB} 2$ critical for the transmission of H5N1 avian influenza viruses in a mammalian host. PLoS Pathog 5, e1000709.

Jiao, P., Tian, G., Li, Y., Deng, G., Jiang, Y., Liu, C., Liu, W., Bu, Z., Kawaoka, Y., and Chen, H. (2008). A single-amino-acid substitution in the NS1 protein changes the pathogenicity of $\mathrm{H} 5 \mathrm{~N} 1$ avian influenza viruses in mice. J Virol 82, 1146-1154.

Li, C., Bu, Z., and Chen, H. (2014). Avian influenza vaccines against H5N1 'bird flu'. Trends Biotech 32, 147-156.

Li, Y., Shi, J., Zhong, G., Deng, G., Tian, G., Ge, J., Zeng, X., Song, J., Zhao, D., Liu, L., et al. (2010). Continued evolution of H5N1 influenza viruses in wild birds, domestic poultry, and humans in China from 2004 to 2009. J Virol 84, 8389-8397.

Li, Z., Chen, H., Jiao, P., Deng, G., Tian, G., Li, Y., Hoffmann, E., Webster, R.G., Matsuoka, Y., and Yu, K. (2005). Molecular basis of replication of duck H5N1 influenza viruses in a mammalian mouse model. J Virol 79, 12058-12064.

Li, Z., Jiang, Y., Jiao, P., Wang, A., Zhao, F., Tian, G., Wang, X., Yu, K., $\mathrm{Bu}, \mathrm{Z}$., and Chen, H. (2006). The NS1 gene contributes to the virulence of H5N1 avian influenza viruses. J Virol 80, 11115-11123.

Liu, J., Chen, P., Jiang, Y., Wu, L., Zeng, X., Tian, G., Ge, J., Kawaoka, Y., $\mathrm{Bu}, \mathrm{Z}$., and Chen, H. (2011). A duck enteritis virus-vectored bivalent live vaccine provides fast and complete protection against $\mathrm{H} 5 \mathrm{~N} 1$ avian influenza virus infection in ducks. J Virol 85, 10989-10998.

Shi, J.Z., Deng, G.H., Liu, P.H., Zhou, J.P., Guan, L.Z., Li, W.H., Li, X.Y., Guo, J., Wang, G.J., Fan, J., et al. (2013). Isolation and characterization of H7N9 viruses from live poultry markets - Implication of the source of current H7N9 infection in humans. Chin Sci Bull 58, 1857-1863.

Shi, J., Deng, G., Kong, H., Gu, C., Ma, S., Yin, X., Zeng, X., Cui, P., Chen, Y., Yang, H., et al. (2017). H7N9 virulent mutants detected in chickens in China pose an increased threat to humans. Cell Res 27, 1409-1421.

Shi, J., Deng, G., Ma, S., Zeng, X., Yin, X., Li, M., Zhang, B., Cui, P., Chen, Y., Yang, H., et al. (2018). Rapid evolution of H7N9 highly pathogenic viruses that emerged in China in 2017. Cell Host Microbe 24, 558-568.e7.

Tian, G., Zhang, S., Li, Y., Bu, Z., Liu, P., Zhou, J., Li, C., Shi, J., Yu, K., and Chen, H. (2005). Protective efficacy in chickens, geese and ducks of an H5N1-inactivated vaccine developed by reverse genetics. Virology 341, 153-162.

Zeng, X., Tian, G., Shi, J., Deng, G., Li, C., and Chen, H. (2018). Vaccination of poultry successfully eliminated human infection with H7N9 virus in China. Sci China Life Sci 61, doi: 10.1007/s11427-0189420-1.

Zhang, Q., Shi, J., Deng, G., Guo, J., Zeng, X., He, X., Kong, H., Gu, C., Li, X., Liu, J., et al. (2013a). H7N9 influenza viruses are transmissible in ferrets by respiratory droplet. Science 341, 410-414.

Zhang, Y., Zhang, Q., Kong, H., Jiang, Y., Gao, Y., Deng, G., Shi, J., Tian, G., Liu, L., Liu, J., et al. (2013b). H5N1 hybrid viruses bearing 2009/ H1N1 virus genes transmit in guinea pigs by respiratory droplet. Science 340, 1459-1463.

Zhu, Q., Yang, H., Chen, W., Cao, W., Zhong, G., Jiao, P., Deng, G., Yu, K., Yang, C., Bu, Z., et al. (2008). A naturally occurring deletion in its NS gene contributes to the attenuation of an $\mathrm{H} 5 \mathrm{~N} 1$ swine influenza virus in chickens. J Virol 82, 220-228. 